\title{
sciendo
}

\section{The short-term turnover estimates in Bosnia and Herzegovina based on the VAT data}

\author{
Fahir Kanlić \\ Department for Industry and Construction Statistics, Agency for statistics of \\ Bosnia and Herzegovina, Sarajevo, Bosnia and Herzegovina \\ fahir.kanlic@bhas.gov.ba
}

Ademir Abdić

Department for Quantitative Methods, School of Economics and Business in Sarajevo, Sarajevo, Bosnia and Herzegovina

ademir.abdic@efsa.unsa.ba

\begin{abstract}
National Statistical Institutes (NSIs) strive to produce short-term business statistics (STS) indicators with the high quality estimates in a timely manner. NSIs are usually faced with the challenges, such as differences in definitions, incompleteness of administrative data, periodicity and timeliness, coverage issues, etc. Administrative Value Added Tax (VAT) turnover data can be used to partially or completely replace survey data for the estimation of short-term business turnover indicators. In this paper, main characteristics of administrative VAT turnover data in Bosnia and Herzegovina will be examined through cleaning of VAT turnover data and matching them with survey data. Hence, the main objective of this study is to investigate the relationship between VAT turnover data and survey data in in Bosnia and Herzegovina. The Monthly Retail Trade Turnover Indices (RTI) for in Bosnia and Herzegovina will be estimated by using administrative VAT turnover data. Spearman's correlation coefficients are used to examine the presence of a linear relationship between VAT turnover data and survey data. Results gained by using survey and administrative VAT turnover data will be compared. Based on the results of the analysis, future challenges and perspectives for expansion of using administrative VAT turnover data will be identified.
\end{abstract}

Keywords: administrative data, business statistics, estimation methods, Value Added Tax (VAT).

JEL classification: $\mathrm{C} 13, \mathrm{C} 81, \mathrm{C} 82, \mathrm{H} 20$.

DOI: $10.2478 /$ crebss-2018-0010

Received: June 20, 2018

Accepted: November 10, 2018

\section{Introduction}

Official National Statistical Institutes (NSIs) monitor the development of IT technology and appropriate software solutions in general, and in particular, using modern statistical methods, tools and available data sources in order to optimize the 
statistical production process. The ultimate goal is to produce accurate, timely and reliable data to meet the needs of data users. NSIs are faced with the need to optimize the data collection process with the aim of reducing the burden on reporting units and the cost of survey conducting, especially when it comes to shortterm business statistical surveys. Modern concepts such as Big Data or the use of available administrative data sources, as a distinctive form of Big Data, make a significant contribution to the optimization, but at the same time represent a difficult and challenging task for the NSIs. This is particularly evident through the linking of administrative data with statistics survey data, in order to use the administrative data for statistical purposes. Given that VAT data on financial turnover (i.e. VAT data) are one of the most important administrative data sources for short-term business statistics (STBS) indicators, this paper will focus on the use of VAT data on financial turnover for statistical purposes. In addition to the introductory section, this paper will describe the basic characteristics of VAT data in Bosnia and Herzegovina (VAT BiH) such as deadlines, definitions, coverage and content of VAT BiH data and their "translation" into the statistical environment through data cleaning, matching of administrative units with Statistical Business Register (SBR) units, variables matching, etc. Based on VAT data, matched with data from the monthly statistical survey on Retail Trade turnover for $\mathrm{BiH}$ (M KPS TRG 01) - section G according to the Classification of $\mathrm{KD} \mathrm{BiH} \mathrm{2010,} \mathrm{an} \mathrm{assessment} \mathrm{of} \mathrm{the} \mathrm{total} \mathrm{turnover} \mathrm{value} \mathrm{and} \mathrm{indices}$ will be carried out for available series for the period January - November 2017. The aim is to determine whether there is a statistically significant difference in the results obtained from the statistical survey turnover data compared to data from the PDV database. At the end of the paper an overview of the future challenges and perspectives in using of VAT data for statistical purposes is given.

Based on the above, the issue of this paper is the theoretical and empirical application of statistical methods in the analysis and use of VAT turnover data from administrative data sources for statistical purposes. The subject of the survey is the estimation of the total turnover value and the calculation of the Retail Trade Turnover Index for BiH (RTI BIH) based on the available VAT data and data from the survey for the Retail Trade activity. For practical reasons and easier data handling, only growth rates from RTI BiH will be calculated. Taking into account the subject of the paper as well as the purpose and purpose of the paper, the null hypothesis is defined as follows: There is no statistically significant difference in the results of RTI BiH obtained by using VAT turnover data and estimated data collected through statistical survey.

\section{Literature review}

The definition of administrative data sources itself and its basic characteristics show that their primary purpose is not to meet the needs of official statistics (United Nations, 2011). Therefore, the use of administrative data sources for statistical purposes has many advantages and disadvantages (Wallgren, Wallgren, 2007). The ESSnet AdminData Project is one of the largest projects in the EU dedicated to the use of administrative data for the production of Business statistics. This project considered practical issues of EU NSIs regarding use of administrative data sources for statistical purposes. As a result of this project, a large number of papers have been prepared with reference to practical experience in using the administrative data for statistical purposes (ESSnet AdminData, 2013). Possibilities of using administrative data sources for statistical purposes have been investigated by many authors with practical examples of NSIs from EU countries (Orchard et al., 2011, Sirviö, 2011, Ortega-Azurduy et al., 2011). 
From statistical point of view, coverage of administrative data is usually incomplete (below certain threshold) and has to be estimated in order to be used for statistical purposes. Ortega-Azurduy et al. (2011) have been focused on estimation methods for incomplete sets of administrative data used in the production of STS. The paper identified two situations that exist when compiling STS using administrative data:

- The Admin data are complete when the estimates have to be produced and can considered being representative for the population.

- The Admin data are not complete when the estimates have to be produced and cannot consider being representative.

By using standard quality indicators (bias, error) they evaluated above mentioned methods and showed that both approaches provide accurate results under stable economic conditions. Sirviö (2011) considered in more experimental - practices about the use of administrative data for monthly turnover estimates in case of unavailability of VAT data when estimates have to be made and in case when VAT data are not representative for the entire population (relatively small group dominated by enterprises belonging to a certain activity).

Somun-Kapetanović et al. (2016) gave detailed review of potential administrative data sources, which could be used for production of STS indicators in BiH. Currently, there are no available scientific papers, which directly deal with the issues of comparing administrative VAT and survey data on financial turnover in production of official short-term turnover indices for $\mathrm{BiH}$. Until now, all financial short-term turnover indicators for $\mathrm{BiH}$ are produced in official statistics institutes in $\mathrm{BiH}$ by using data collected through statistical surveys. This paper will significantly contribute to theoretical and empirical analysis of VAT turnover data, examination of their characteristics and use in production of official turnover indices for $\mathrm{BiH}$.

\section{Using administrative data for statistical purposes}

Administrative data sources are a very topical issue in many professional papers describing the different practices of NSIs in their use for statistical purposes. A large number of NSIs of the European Union countries intensively use various administrative data sources for statistical purposes. Examples of good practices regarding the development and availability of administrative data sources and their successful use are certainly the Nordic countries (Sweden, Denmark and Norway) and their NSIs. However, one of the first limiting factors affecting their use is the issue of data confidentiality. In addition, the problem with which NSIs in Europe and the world generally face is unavailability of administrative data sources in the timeliness and periodicity required to produce statistical indicators, most commonly the STBS indicators. In addition, one of the problems of using VAT data for statistical purposes may be the difference in definitions.

The NSIs practice has shown that, for the successful use of VAT turnover data in statistical purposes, it is necessary to fulfil at least two conditions: that the definitions of financial turnover are aligned and that the periodicity of these data is appropriate. Among the most important factors influencing the use of administrative data sources in statistics (United Nations, 2011) are: observation units, variables definition, and timeliness, inconsistency between different sources, missing data and resistance to change (frequent revisions). Most NSIs rely on administrative data partially, while a number of NSIs use administrative data completely. In other words, they use the total or partial replacement of statistical data with administrative data. In the EU countries, the partial use of administrative data on financial turnover is most often the result of data incompleteness, either due to the late submission of data by 
the enterprise or due to prescribed different periodicity for different sizes of the enterprises. The practices of NSIs of individual EU countries have been described in the papers (Orchard et al., 2011, Sirviö, 2011, Ortega-Azurduy et al., 2011), as a result of The ESSnet Admin Data Project. Large companies with their data on realized financial turnovers directly influence (participation in most cases between $65 \%$ and $90 \%$ of total turnover) on the phenomena movement. In addition, although large companies in all countries are VAT taxpayers, due to the complexity of their organizational structure (often organized as a group of companies) and their large influence on the level of phenomena, they must be monitored through survey.

For small and medium companies, it is possible to entirely rely on VAT turnover data. The first step in using the VAT turnover data is certainly matching with the Statistical Business Registry (SBR) and properly defining the enterprise's code of activity, as well as the coverage of the units, i.e. whether there is under coverage between administrative and statistical data (Sanderson et al., 2013). In order to fully use VAT data, it is necessary to analyse the completeness of data between the periods (missing values). In case administrative data are not complete, the most often used methods are the imputations of the turnover value from the previous period, use of the same period of the previous year or the average of the year.

After the imputations have been made, it is necessary to check the imputation effects on the total value. It is particularly important to consider the fact that the estimate of turnover data is performed at micro level (enterprise) or macro level (aggregation to activity level or higher aggregation levels according to Classification of Activities). Incorrectly defined activity code of enterprise may have direct effect on the bias of data.

\section{VAT data in Bosnia and Herzegovina}

The statistical system in $\mathrm{BiH}$ follows the complex administrative and organizational structure of $\mathrm{BiH}$, reflecting the quality and availability of administrative data sources for statistical purposes. A smaller problem is represented by those areas of society that are regulated at the state level in a systemic way, while certain areas are regulated in the exclusive competence of the entity level.

A more detailed review and description of some of the most important administrative data sources in $\mathrm{BiH}$ for business statistics is described in the paper of (Somun-Kapetanović et al., 2016). Indirect Taxation Authority of $\mathrm{BiH}$ (ITA BiH) is a state-level institution in charge of collecting indirect taxes (VAT and customs) for the entire BiH. Throughout the form "P PDV", ITA electronically collects the data on the realized turnover and the corresponding amount of VAT. According to the Law on VAT of BiH, all business units, which have annual revenue more than 50,000 KM, are obliged to register as VAT taxpayers and to pay VAT. In addition, VAT taxpayers are business units registered for performing foreign trade, international forwarding business units and manufacturers of excisable products in Bosnia and Herzegovina. VAT return forms are submitted monthly, up to $10^{\text {th }}$ day in the current month for the previous (reference) month. Unique VAT rate of $17 \%$ is charged in $\mathrm{BiH}$. In addition to enterprise turnover data, VAT data include also turnover data for both entrepreneurs as well as physical entities importing certain goods and paying them customs and VAT. Agency for statistics of $\mathrm{BiH}$ (BHAS) receives from ITA BiH the following data on turnover from the VAT return, which are of importance for business statistics: the sale/delivery value, the value of the export and the value of the deliveries exempt from VAT payments. Sum of these three types of turnover represent total turnover. According to EU STS Regulation, Variable 120 - Turnover for all STS domains, is defined in the following way: "Turnover comprises the totals invoiced by the observation unit 
during the reference period, and this corresponds to market sales of goods or services supplied to third parties. Turnover also includes all other charges (transport, packaging, etc.) passed on to the customer, even if these charges are listed separately in the invoice." Eurostat requests from NSIs to produce STS monthly indicators up to 30th day of the month for the previous (reference) month, with the exception of 15 days for small countries (less than 1\% of GDP in respect of GDP of the European Union), in accordance with the valid EU STS Reg. 1165/98.

After a long harmonization of the procedure and contents of the VAT data exchange, BHAS received the VAT data from ITA BiH for the first time as of 22 June 2017, based on the signed Protocol on Data Exchange between these two institutions. It was agreed that ITA BiH would deliver the VAT database to BHAS as of $22^{\text {nd }}$ in the month, with precisely defined fields for all businesses registered as VAT payers. This database contains data for the previous (reference) month as well as the previous 12 months. VAT turnover data is of great importance and usability to BHAS due to data collection periodicity, data delivery deadlines from ITA BiH to BHAS and BHAS deadlines for the production of monthly/quarterly turnover indicators for $\mathrm{BiH}$. RTI BiH is published each 28th day in the month for previous (reference) month. In comparison with other countries in the region and EU, BHAS is in position that is more favourable when it comes to timeliness and periodicity. The access to the VAT database leaves BHAS with capabilities to replace, partially or fully, the survey data with data from VAT base. It occurs that legal units correct the turnover and VAT data for the previous periods through VAT database, even up to five years. From the perspective of official statistics, data correction practices may be reflected in the revision of the data included in published turnover data by BHAS. Given that the production of the STS turnover indicators in BiH is based solely on survey data, VAT data are very useful input for analysis and possible future use for statistical purposes. Due to availability of short VAT data series for BiH and lack of individual data for units from the survey, majority of the analysis will be performed on macro level (aggregated data). This is the first paper, which deals with the possibility of using VAT turnover data for statistical purposes in $\mathrm{BiH}$ and should serve as a motive for further research on this or similar topics.

\section{Monthly Retail Trade Index (RTI) in Bosnia and Herzegovina}

For purpose of this paper, we will briefly consider the basic methodological settings of Monthly survey on Retail Trade Turnover for BiH (M KPS TRG 01). This survey comprises business entities/legal units, which are registered, by the main activity, within Retail trade activity - section G, division G47 according to KD BiH 2010, except retail trade of motor vehicles and motorcycles. In addition, businesses, which are, according to their main activity, classified in other activities, but also performing Retail trade activity, are included while entrepreneurs are not included in this survey. Based on sample frame, taken from SBR, a two-stage stratified sample of statistical units was selected.

For collecting and processing the data, the combined method of sample and full coverage is used depending on size of the enterprise (financial class). Primary stratification variable is the financial data (turnover) from the sample frame and as second stratification variable, the number of persons employed is used. Stratification variables in SBR are available in classes, not as individual figures. Business entities/legal units with annual financial data less than 100,000 KM are excluded from the sample frame. Sample frame for $\mathrm{BiH}$ in 2017 covered totally 2,807 reporting units, while the selected sample for BiH covers 1,460 units, as follows: 874 for $\mathrm{FBiH}, 457$ for RS and 129 for $\mathrm{BD} \mathrm{BiH}$. 
Data are collected in a traditional way (postal survey - paper questionnaire). After correction of initial weights for non-response, ratio estimator is used for final calculation of totals of enterprises per strata. From methodological point of view, obstacles, which have an influence on quality of data used for RTI BiH calculation, are method of data collection and use of old financial data for stratification and calculation of totals (available for year $t-2$ ). Overall response rate is high, approximately $97 \%$.

\section{Comparison of VAT data and survey data on financial turnover for Retail Trade Turnover for BiH}

Upon receipt of the VAT turnover data, the need to ensure the protection of data confidentiality was imposed as the first priority activity for BHAS. Hence, initial matching of the data from VAT database with data from SBR was done. For each matched legal entity from the VAT database with SBR data, a randomly selected number replaces the actual 13-digit ID number. This is done because protection of data confidentiality. Given that the business activity codes in ITA's VAT database have not been updated in the last 5 years (the old Classification of Activities KD BiH 2005, EU NACE Rev.1.1 is used), for purposes of analysing and processing this data the activity codes from SBR are used for matched legal units. In this case, by using code of activity from SBR for each reporting unit, we ensured that the codes are updated at least on quarterly basis from different data sources. Monthly series on VAT turnover data also include turnover data for entrepreneurs, while SBR does not include stratification variables data for them.

Table 1 Number of enterprises and entrepreneurs in VAT database* for Retail trade activity for $\mathrm{BiH}, 2017$

\begin{tabular}{|c|c|c|c|c|c|}
\hline \multirow{2}{*}{ Region } & \multirow{2}{*}{$\begin{array}{c}\text { Total no. } \\
\text { of } \\
\text { enterprises }\end{array}$} & $\begin{array}{c}\text { active } \\
\text { enterprises in } \\
\text { SBR }\end{array}$ & $\begin{array}{c}\text { other status } \\
\text { in SBR } \\
\text { (inactive) }\end{array}$ & $\begin{array}{c}\text { out of } \\
\text { scope of } \\
\text { SBR }\end{array}$ & $\begin{array}{c}\text { No. of } \\
\text { entrepreneurs }\end{array}$ \\
\hline Federation of BiH & 2,653 & 2,391 & 191 & 71 & 1,894 \\
Republika Srpska & 871 & 785 & 63 & 23 & 1,940 \\
Brcko District BiH & 215 & 181 & 22 & 12 & 198 \\
Bosnia and Herzegovina & 3,739 & 3,357 & 276 & 106 & 4,032 \\
\hline
\end{tabular}

* Taxpayers with turnover higher than 50,000 KM.

Source: Authors' creation.

As shown in Table 1, by aggregating the units in the VAT database with units in SBR for the Retail Division (G47) in 2017, 3,357 legal units were matched (activity status in SBR's "active" and "newly born"), while 276 legal entities identified in the VAT database and in the SBR have the status of activity "not active", "dormant" and "unknown".

Altogether 106 legal units are located outside the SBR in the observed period, but have the data presented in the VAT database. It was determined by verification that these are legal entities that are not recorded in SBR due to the characteristics of business demography (newly born in 2017).

In addition, for the purposes of making analysis of data consistency between administrative and survey data sources, we matched the same enterprises from the sample frame and selected sample for M KPS TRG 01 survey. Main findings are presented in Table 2. 
Table 2 Number of units in sample frame, sample and VAT database for Retail trade survey for $\mathrm{BiH}, 2017$

\begin{tabular}{|c|c|c|c|c|c|c|c|c|}
\hline \multirow[b]{3}{*}{ Region } & \multicolumn{4}{|c|}{ No. of enterprises - sample frame** } & \multicolumn{4}{|c|}{ No. of enterprises - sample } \\
\hline & \multirow[b]{2}{*}{$\begin{array}{c}\text { Number of } \\
\text { enterprises } \\
\text { in SBR }\end{array}$} & \multicolumn{2}{|c|}{ Paired with VAT data } & \multirow[b]{2}{*}{$\begin{array}{c}\text { Unpai- } \\
\text { red }\end{array}$} & \multirow[b]{2}{*}{$\begin{array}{c}\text { Number of } \\
\text { enterprises } \\
\text { in SBR }\end{array}$} & \multicolumn{2}{|c|}{ Paired with VAT data } & \multirow[b]{2}{*}{$\begin{array}{l}\text { Unpa- } \\
\text { ired }\end{array}$} \\
\hline & & $\begin{array}{c}\text { VAT } \\
\text { turnover } \\
\text { value } \geq 0\end{array}$ & $\begin{array}{c}\text { Out of which } \\
\text { no. of } \\
\text { enterprises, } \\
\text { VAT turnover } \\
\text { value }=0\end{array}$ & & & $\begin{array}{c}\text { VAT } \\
\text { turnover } \\
\text { value } \geq 0\end{array}$ & $\begin{array}{c}\text { Out of which } \\
\text { no. of } \\
\text { enterprises, } \\
\text { VAT turnover } \\
\text { value }=0\end{array}$ & \\
\hline \multirow{4}{*}{$\begin{array}{l}\text { Federation of BiH } \\
\text { Republika Srpska } \\
\text { Brcko District BiH } \\
\text { Bosnia and } \\
\text { Herzegovina }\end{array}$} & 1944 & 1887 & 64 & 57 & 874 & 864 & 17 & 10 \\
\hline & 734 & 711 & 24 & 23 & 457 & 443 & 17 & 14 \\
\hline & 129 & 123 & 5 & 6 & 129 & 123 & 5 & 6 \\
\hline & 2807 & 2721 & 93 & 86 & 1460 & 1430 & 39 & 30 \\
\hline
\end{tabular}

** Criteria: financial turnover higher than 100,000 KM. Source: Authors' creation.

Comparing the data of the units selected in the sample frame for the M KPS TRG01 survey with units in the VAT base, of total number of 2807 units, 86 (3.1\%) remained unmatched because do not have VAT data. Preliminary analysis found that these are units whose status is the result of changes in business demography (closed enterprises, dormant). Consequently, 30 units $(2.1 \%)$ of the selected sample of units remained unmatched. These changes occurred partially because the frame of the legal units for survey conducting was taken with the status of SBR from year $t-1$. Data for stratification variables in SBR are available from the year t-2, compared to the reference year. Of course, an update is done with the data available through statistical surveys. In the first phase, an analysis of the degree of data revision for previous months was made for each ITA's BiH delivery of available 13-month data series to BHAS. From the entities' point of view (Federation of BiH, Republika Srpska and Brcko District $\mathrm{BiH}$ ), data revision at the legal unit level for total retail trade (G47 to $\mathrm{KD} \mathrm{BiH} \mathrm{2010)} \mathrm{occurs} \mathrm{from} \mathrm{month} \mathrm{to} \mathrm{month.} \mathrm{On} \mathrm{the} \mathrm{BiH} \mathrm{level,} \mathrm{an} \mathrm{average} \mathrm{revision} \mathrm{is}$ done for 25 to 30 legal units (out of 2721 matched legal units). The effect of the revision observed according to the change in the value of turnover on total Retail trade (G47) for BiH level, ranging from $-0.12 \%$ to $+0.56 \%$ per month. At the level of the stratum, this difference is slightly higher (up to $+12.5 \%$ ), but due to the relative importance of the stratum/the most detailed level of activity aggregation, the impact on total value is negligible and does not significantly affect the change of total Retail trade turnover for $\mathrm{BiH}$. For future analysis, it is certainly necessary to observe a longer set of data at the unit level and to track the size of the revision in order to determine the data revision policy. In addition, analysis of the VAT data for G47, showed insignificant presence of negative turnover values stated in VAT return form. Of 3739 legal entities in the VAT database, 23 units were reported negative turnover values. Of the total realized turnover of units in division G47 stated in VAT database for the first 11 months of 2017, the share of recorded negative turnover values was $0.0086 \%$. Their influences of negative values are negligible for the total phenomenon and are treated as zero in further processing. The next step is comparison of turnover data from the VAT database with the statistical data from the monthly survey M KPS TRG 01 for BiH for the period January - November 2017. The following three cases have been considered in this paper:

- CASE 1: Comparison of monthly turnover growth rates from the M KPS TRG 01 survey (\%SUR), estimated for the total sample frame population - 2807 enterprises (see Table 2) with monthly turnover growth rates from the VAT 
database for the same enterprises like in sample frame (\%VATFR). Growth rates are calculated for total G47 and main aggregates.

- CASE 2: Comparison of monthly growth rates from the M KPS TRG 01 survey (\%SUR), estimated for the total population, with growth rates of entire VAT database - 3739 units (see Table 1), entrepreneurs included (\%VATall+ENTPRN). Growth rates are calculated for total G47 and main aggregates.

- CASE 3: Comparison of monthly growth rates from the M KPS TRG 01 survey (\%SUR), estimated for the total population, with growth rates of entire VAT database - 3739 units (see Table 1), entrepreneurs excluded (\%VATallENTPRN). Growth rates are calculated for total G47 and main aggregates.

In all three cases, a comparison of monthly growth rates movement was done for the period January - November 2017. Growth rates were calculated based on absolute values of turnover for the aforementioned period. The comparison is based on the basic economic aggregates for the Retail trade for $\mathrm{BiH}$, measured by their relative importance (G471 - Retail sale of non-specialized stores and G472 - Retail sale of food, beverages and tobacco in specialized stores, G473 - Retail sale of automotive fuel in specialized stores and Other retail trade (G474 to G479).

Figure 1 show the trend of monthly growth rates of Retail trade turnover for $\mathrm{BiH}$ for the above cases, for aggregates $\mathrm{G} 471$ and $\mathrm{G} 472$ while Figure 2 shows the trend of monthly growth rates for $\mathrm{G} 474$ to $\mathrm{G} 479$ for $\mathrm{BiH}$.

Aggregation was done according to the relative importance of each branch in total turnover. In 2017, groups G471 and G472 had approximately $45 \%$ share of total Retail trade turnover for BiH, G473 with 25\%, and G474 - G479 groups with $30 \%$ share. Based on the comparison of the chained growth rates of Retail trade turnover for $\mathrm{BiH}$ in 2017 for these cases, we conclude that their movement is relatively stable and that there is no significant oscillation in the movement of the occurrence level nor movements in the opposite direction. Data for entrepreneurs from the VAT data were analysed in order to examine their impact on the overall phenomena, since they were not included in the M KPS TRG 01 survey. It was found that their impact on the overall turnover averaged $10 \%$. Turnover data flow for entrepreneurs does not show a significant seasonal impact, as it is the case with VAT and survey data for enterprises.

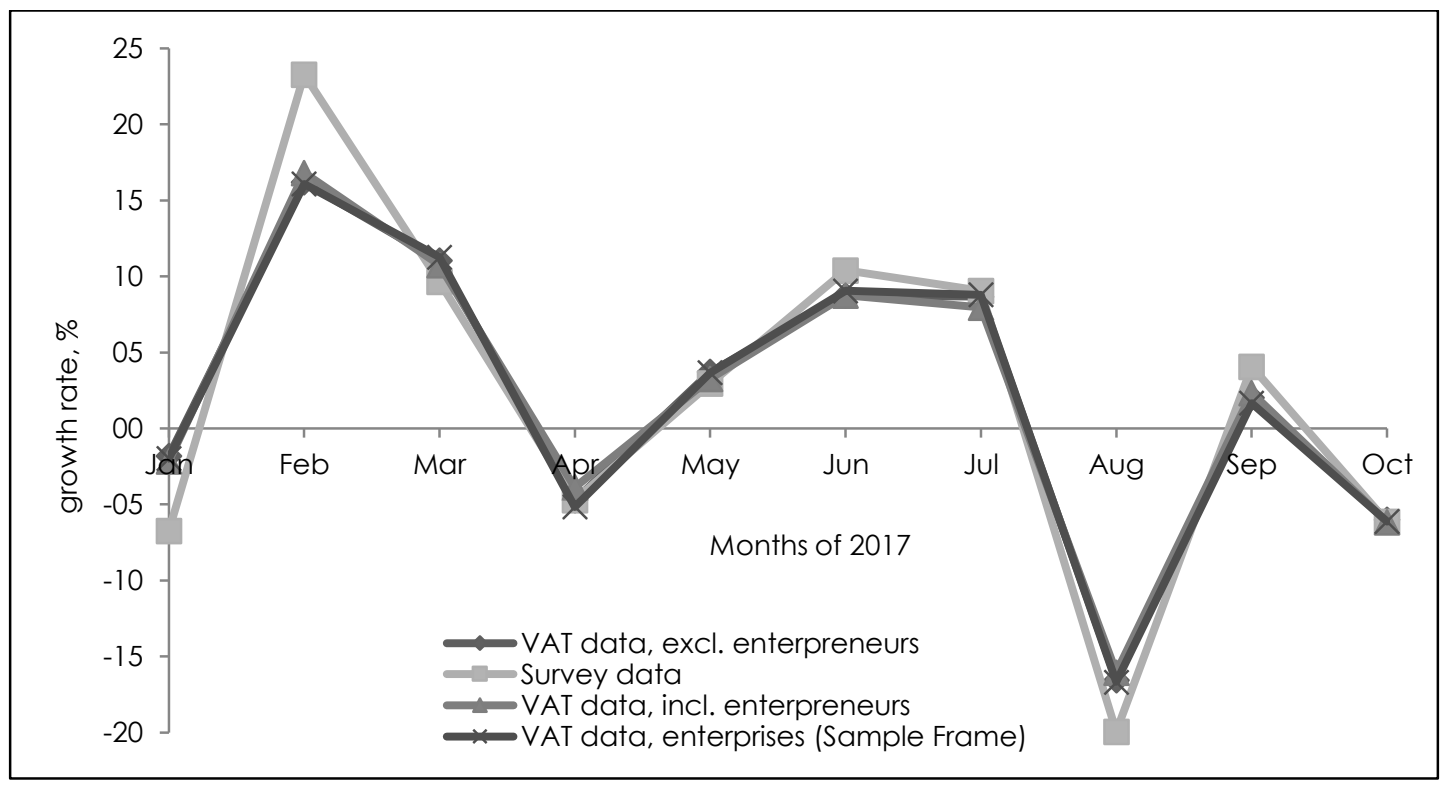

Figure 1 Monthly growth rates of RTI for BiH, G471 and 472, 2017 Source: Authors' creation. 


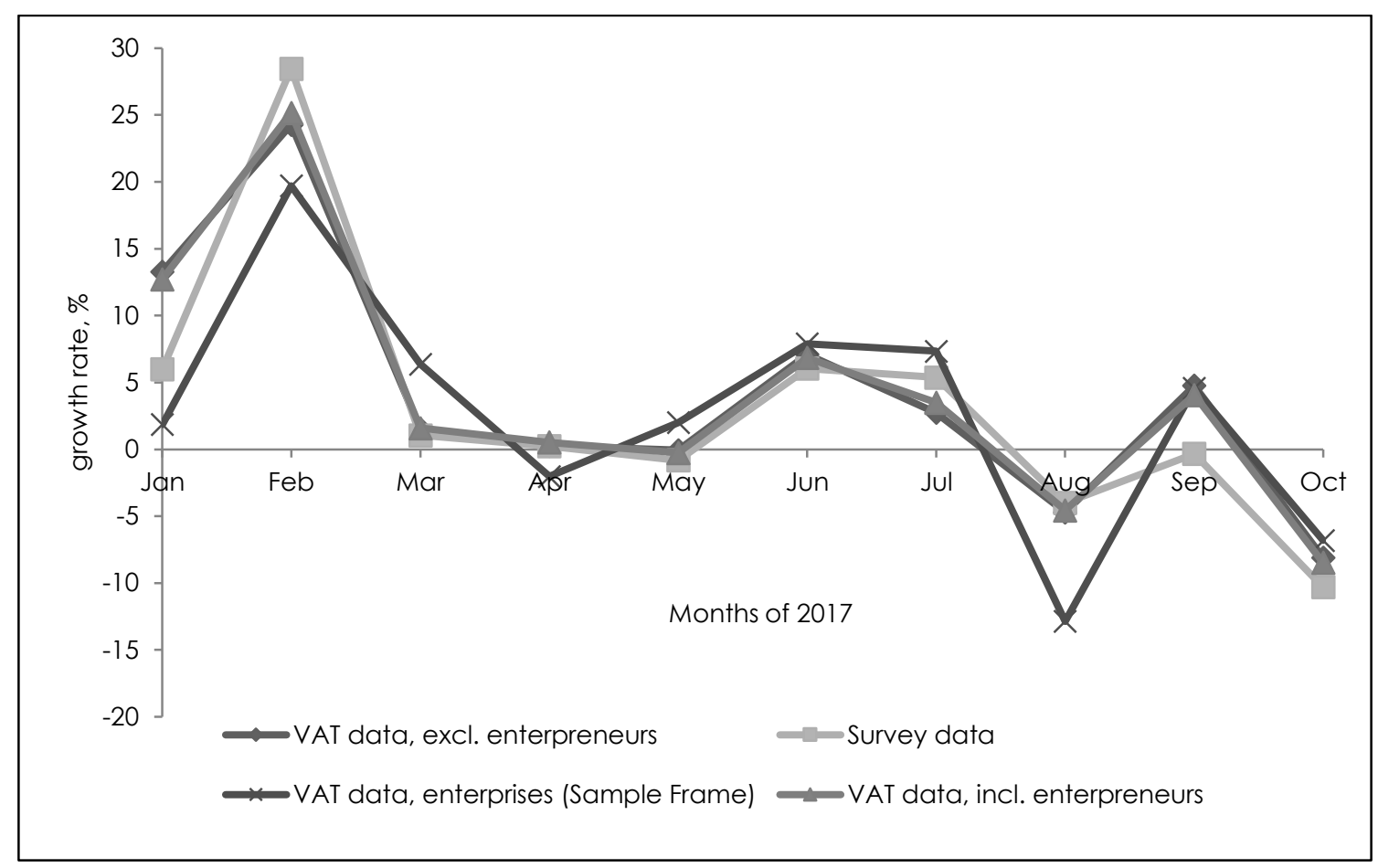

Figure 2 Monthly growth rates of RTI for BiH, G474 to G479, 2017

Source: Authors' creation.

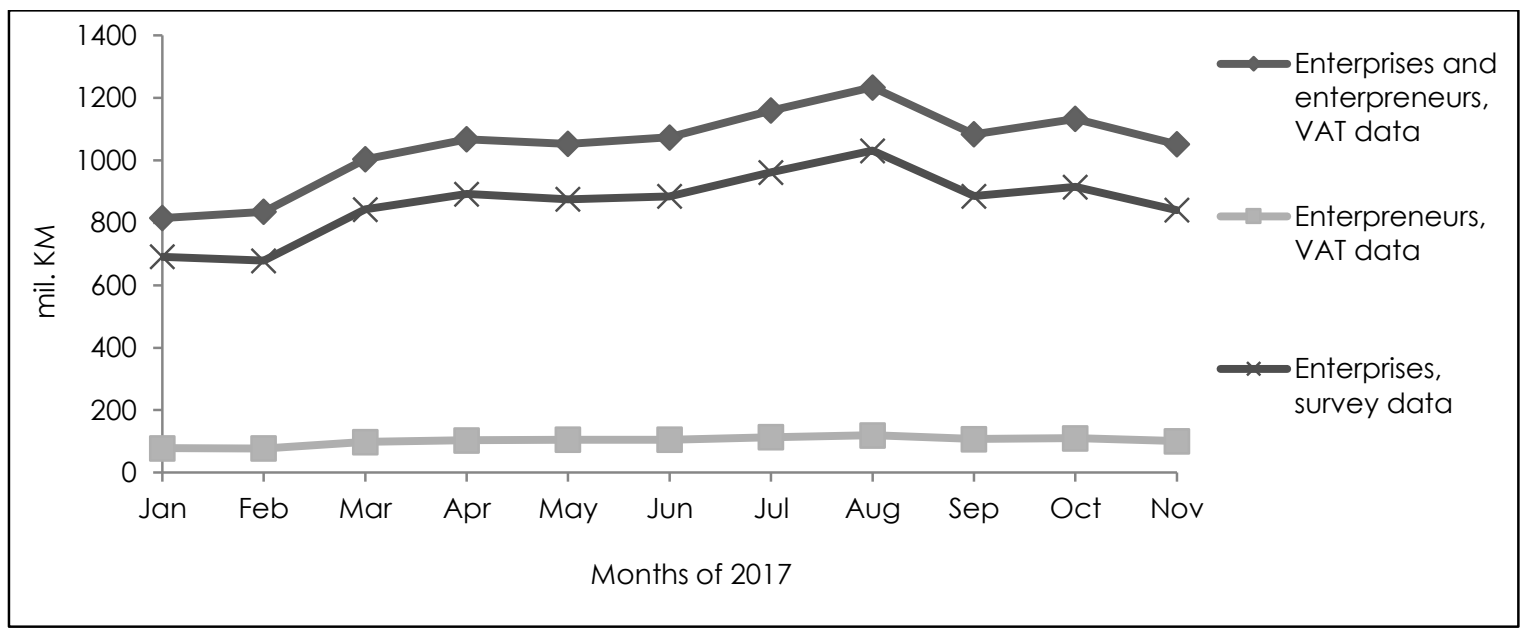

Figure 3 Monthly Retail total trade turnover for BiH (G47), 2017

Source: Authors' creation.

In addition, Figure 3 shows the movement of the nominal value of financial turnover data collected through survey and all data from the VAT database (data for enterprises and entrepreneurs included). Except for the difference in the level of phenomena measured by the nominal value of the turnover due to included data on entrepreneurs, the same trend of the phenomena movement is noticed, with clear seasonal effect generated by the turnover data for the enterprises. In order to test the differences in turnover growth rates calculated from the VAT database and M KPS TRG 01 survey for three cases above mentioned, the Wilcoxon Signed Ranks Test was performed and results are presented in Table 3: 
Table 3 Wilcoxon Sign Ranked Test of monthly Retail trade turnover growth rates for $\mathrm{BiH}$ in 2017, by levels of activity aggregation

\begin{tabular}{|l|c|c|c|}
\hline \multicolumn{1}{|c|}{ Levels } & $\begin{array}{c}\text { CASE 1 } \\
\text { \%SUR and \% VATF }\end{array}$ & $\begin{array}{c}\text { CASE 2 } \\
\text { \%SUR - \%VATall+ENTPRN }\end{array}$ & $\begin{array}{c}\text { CASE 3 } \\
\text { \%SUR- \%VATall-ENTPRN }\end{array}$ \\
\hline G471 and G472 & $Z=-0,089(p=0,929)$ & $Z=-0,178(p=0,859)$ & $Z=-0,000(p=1,000)$ \\
G473 & $Z=-1,156(p=0,248)$ & $Z=-1,778(p=0,075)$ & $Z=-1,867(p=0,062)$ \\
G474 to G479 & $Z=-0,445(p=0,657)$ & $Z=-1,156(p=0,248)$ & $Z=-1,156(p=0,248)$ \\
TOTAL G47 & $Z=-1,334(p=0,182)$ & $Z=-1,245(p=0,213)$ & $Z=-1,245(p=0,213)$ \\
\hline
\end{tabular}

Source: Authors' creation.

The test results shows that there is no statistically significant difference in turnover growth rates between VAT and survey data for the period January - November 2017, regardless the level of aggregation of activity and comparisons of sets from different data sources (VAT and survey data). In addition, Spearman's correlation coefficients indicate almost perfect correlation of turnover growth rates from VAT and survey data for Retail trade statistics in $\mathrm{BiH}$, as given in Table 4.

Table 4 Spearman's correlation coefficients for Retail trade growth rates, $\mathrm{BiH}, 2017$

\begin{tabular}{|c|c|c|c|c|}
\hline & Case 1 & Case 2 & Case 3 \\
\hline & & \%VATF & \%VATall+ENTPRN & \%VATall-ENTPRN \\
\hline \multirow{3}{*}{$\begin{array}{c}\text { \%SUR } \\
\text { G471 and } \\
\text { G472 }\end{array}$} & Correlation Coefficient & $.936^{* *}$ & $.955^{* *}$ & $.936^{* *}$ \\
\hline & Sig. (2-tailed) & .000 & .000 & .000 \\
\hline & $\mathrm{N}$ & 11 & 11 & 11 \\
\hline \multirow{3}{*}{$\begin{array}{l}\text { \%SUR } \\
\text { G473 }\end{array}$} & Correlation Coefficient & $.982^{* *}$ & $.982^{* *}$ & $.982^{* *}$ \\
\hline & Sig. (2-tailed) & .000 & .000 & .000 \\
\hline & $\mathrm{N}$ & 11 & 11 & 11 \\
\hline \multirow{3}{*}{$\begin{array}{c}\text { \%SUR } \\
\text { G474 - G479 }\end{array}$} & Correlation Coefficient & $.936^{* *}$ & $.918^{* *}$ & $.891^{* *}$ \\
\hline & Sig. (2-tailed) & .000 & .000 & .000 \\
\hline & $\mathrm{N}$ & 11 & 11 & 11 \\
\hline \multirow{3}{*}{$\begin{array}{c}\text { \%SUR } \\
\text { Total G47 }\end{array}$} & Correlation Coefficient & $1.000^{* *}$ & $.991^{* *}$ & $.991^{* *}$ \\
\hline & Sig. (2-tailed) & .000 & .000 & .000 \\
\hline & $\mathrm{N}$ & 11 & 11 & 11 \\
\hline
\end{tabular}

**. Correlation is significant at the 0.01 level (2-tailed)

*. Correlation is significant at the 0.05 level (2-tailed).

Source: Authors' creation

This analysis shows rough estimates of turnover totals from both data sources. Comparison with previous analyses in $\mathrm{BiH}$ is not possible because this paper consider this topic for the first time. Results show that VAT turnover data have big potential for turnover estimates in $\mathrm{BiH}$, at least for small and medium enterprises (partial replacement of survey data with administrative data). Many NSIs in EU use the same practices and results are very similar (ESSnet Admin Data, 2013).

\section{Future challenges and prospects in using VAT data in official statistics of BiH}

The start of regular monthly VAT data delivery to BHAS by ITA BiH represents a significant step forward for BiH's official statistics, whose ultimate goal is to improve the quality of STBS indicators for BiH. However, successful reliance on VAT data requires a very serious and systematic approach to solving methodological differences in the treatment of VAT turnover data. Drawing on the practical experience of other NSIs and the theoretical and methodological aspects of the use of VAT data for statistical purposes, the main challenges for the future use of VAT turnover data in BiH statistics are: 
- possibility of changing the periodicity of VAT turnover data collection,

- change of registration threshold for VAT taxpayers,

- irregular updating of activity code of the VAT taxpayer by ITA BiH,

- the way of applying VAT data in production of STS indicators by all three statistical institutions in $\mathrm{BiH}$,

- the availability of human, financial and IT resources that would enable the use of PDV data for statistical purposes, cooperation between statisticians and ITA $\mathrm{BiH}$ staff with the aim of solving methodological and practical issues related to VAT data,

- availability of individual survey and SBR data that will serve as a good input for analysis and assessment, especially when it comes to the delinearization of the KAUs, etc.

Through the complete or partial exchange of survey data with administrative data, the use of VAT turnover data for the production of official statistics in BiH has a good prospect. It is necessary, above all, to form a constant expert Working Group, which will be made of ITA BiH and BHAS representatives, which will deal with methodological issues and point to discrepancies in results with the aim of adequate treatment. BHAS should be consulted for any changes to the legal regulations regarding the turnover and VAT data, taking into account the needs of official statistics. In addition, strategy of using VAT data for statistical purposes should be established, the methodology of using VAT data for individual surveys, tailored to their needs should be adopted and adequate IT support provided.

\section{Conclusion}

This paper presents the basic characteristics of the VAT turnover data, with an overview of their potential for practical use in official statistics. The characteristics of the VAT data in BiH are described. Based on the data available from monthly survey M KPS TRG 01 for $\mathrm{BiH}$, their matching with VAT data was performed on macro level. Results obtained by using the VAT turnover data and turnover data obtained through the survey were tested on aggregated level. The null hypothesis has been proven - there is no statistically significant difference in the results produced from these two sources. Results of performed analysis suggested that VAT turnover data could be used for production of short-term turnover variables in $\mathrm{BiH}$, which contribute to optimization of statistical production process through minimizing costs of survey conducting, reduction of time needed for data collection, reduction of burden on respondents and increase the coverage of units for the survey.

Since this is the first scientific paper dealing with this issue in $\mathrm{BiH}$, this paper is an excellent basis for future research with focus on a more detailed analysis of data imputation for missing values from both sources, measuring imputation effects and the use of other statistical methods and models for estimating total turnover data. Based on obtained results of analysis, administrative VAT turnover data are useful for partial replacement of survey data with administrative data, for imputation of missing values as well as for comparison of results received through different data sources. The future use of VAT turnover data in $\mathrm{BiH}$ will require a serious and studious approach to the analysis of VAT turnover data on micro level, their translation into the statistical environment with the aim of their use for production of quality shortterm statistical turnover indicators. 


\section{References}

1. ESSnet Admin Data (2013). Use of Administrative and Accounts Data for Business Statistics. Available at https://ec.europa.eu/eurostat/cros/content/use-administrative-andaccounts-data-business-statistics_en [25 January 2018].

2. Orchard, C., Langford, A., Moore, K. (2011). National practices of the use of administrative and accounts data in UK Short-Term Business Statistics. Available at https://ec.europa.eu/eurostat/cros/system/files/SGA\%202010_Deliverable_4.2.pdf [25 January 2018].

3. Ortega-Azurduy, S., Vlag, P., Karus, E. (2011). The use of admin data for monthly and quarterly estimates: Common issues and challenges in Estonia, Finland, Germany, Italy, Lithuania, the Netherlands and the United Kingdom. Available at https://ec.europa.eu/eurostat/cros/system/files/SGA\%202010_Deliverable_4.9.pdf [25 January 2018].

4. Sanderson, R., Woods, J., Jones, T., Morgan, G., Lewis, D., Davies, J. (2013). UK report on estimation of investment variables. Available at https://ec.europa.eu/eurostat/cros/system/files/SGA\%202011_Deliverable_3.2.pdf [25 January 2018].

5. Sirviö, M. (2011). Turnover Indices (Incl. Retail Trade) and Value Added Tax (VAT) Data. Available at https://ec.europa.eu/eurostat/cros/content/admindata-sga-1_en [25 January 2018].

6. Somun-Kapetanović, R., Resić, E., Kanlić, F. (2016). Use of administrative data for statistical purposes - challenges and perspectives in use of administrative data in business statistics of Bosnia and Herzegovina. Dumičić, K., Erjavec, N., Pejić Bach, M., Eds., Proceedings of the ISCCRO - International Statistical Conference in Croatia, Zagreb, Croatia, May 05-06 2016, Vol. 1, No. 1, Croatian Statistical Association, Zagreb, 2016. pp. 55-62.

7. United Nations (2011). Using Administrative and Secondary Sources for Official Statistics. A Handbook of Principles and Practices. Available at https://unstats.un.org/unsd/EconStatKB/KnowledgebaseArticle10349.aspx [20 January 2018].

8. Wallgren, A., Wallgren, B. (2007). Register-based Statistics; Administrative Data for Statistical Purposes. John Wiley \&Sons, Chichester.

\section{About the authors}

Fahir Kanlić has a Bachelor Degree in Economics. He is the Head of Department for Industry and Construction Statistics in the Agency for Statistics of Bosnia and Herzegovina; he is a project coordinator for development of monthly/quarterly indicators on industrial production, producer price indices in construction, and introduction of administrative data sources in production of official statistics in Bosnia and Herzegovina. Scientific interest: statistics, econometrics, quantitative economics. He is the author or a co-author of several scientific papers, methodological documents and thematic bulletins. He can be contacted at: fahir.kanlic@bhas.gov.ba.

Ademir Abdić has a Master Degree in Economics and works at the School of Economics and Business of the University of Sarajevo. He is a Senior Teaching Assistant for the following modules: Statistics in Economics and Management, Business Statistics, Applied Statistical Analysis. Scientific interest: statistics, econometrics, quantitative economics. He has been a co-author of two books and has published several scientific papers. He is a member of the organizing committee of the International Conference on Official Statistics: Challenges, Opportunities and Future Directions (ICOS2017). He can be contacted at: ademir.abdic@efsa.unsa.ba. 